University of Nebraska - Lincoln

DigitalCommons@University of Nebraska - Lincoln

Educational Psychology Papers and

Publications

Educational Psychology, Department of

2009

Human Trafficking: A Review for Mental Health Professionals

Oksana Yakushko

University of Nebraska-Lincoln, oyakushko2@unl.edu

Follow this and additional works at: https://digitalcommons.unl.edu/edpsychpapers

Part of the Educational Psychology Commons

Yakushko, Oksana, "Human Trafficking: A Review for Mental Health Professionals" (2009). Educational Psychology Papers and Publications. 91.

https://digitalcommons.unl.edu/edpsychpapers/91

This Article is brought to you for free and open access by the Educational Psychology, Department of at DigitalCommons@University of Nebraska - Lincoln. It has been accepted for inclusion in Educational Psychology Papers and Publications by an authorized administrator of DigitalCommons@University of Nebraska - Lincoln. 
Published in International Journal for the Advancement of Counselling 31 (2009), pp. 158-167;

doi: 10.1007/s10447-009-9075-3 Copyright () 2009 Springer Science+Business Media, LLC.

Used by permission.

Submitted December 9, 2008; accepted April 20, 2009; published online July 30, 2009.

\title{
Human Trafficking: A Review for Mental Health Professionals
}

\author{
Oksana Yakushko \\ University of Nebraska-Lincoln, Lincoln, Nebraska USA; email oyakushko@gmail.com
}

\begin{abstract}
This article provides a review of current research on human trafficking for mental health practitioners and scholars. In addition to an overview of definitions, causes and processes of trafficking, the article highlights mental health consequences of trafficking along with suggestions for treatment of survivors. Directions for counseling services, prevention, policy work and international involvement are also discussed.
\end{abstract}

Keywords: human trafficking, human slavery, counseling, prevention, international

\section{Introduction}

Human trafficking has begun to attract the attention of the world community (Bales 2005; Bales and Lize 2005; European Commission 2004; Gozdziak and Collett 2005; Omelaniuk 2005; Seelke and Siskin 2008). Although trafficking is not a new phenomenon (Gozdziak and Collett 2005; Monzini 2005), increases in trafficking and enslavement of children, women and men around the world has triggered since the early 1990's the sustained attention of the international community (Doezema 2002; Kelly and Regan 2000). Organizations such as the United Nations (UN), International Organization of Migration (IOM), International Labor Organization (ILO) and UNICEF have given increasing attention to this phenomenon, as has a number of separate countries. The United States, for example, ratified the "Trafficking Victims Protection Act" (TVPA) in 2000.

In addition to increasing awareness on both national and international political levels, human trafficking has also started to enter the popular consciousness. Publications such as the New York Times and National Geographic have included several extended special articles on human trafficking, special programs on the topic have been produced by public broadcasting (PBS) and other TV production companies, and films have appeared on the theme, such as Dirty Pretty Things and Holly. Mental health practitioners and their representative organizations also have begun to respond to the realities of modern-day human slavery and its impact on individuals (e.g., Yakushko 2008) and societies. However, 
mental health publications have included only minimal attention to the topic and its effects, and organizations have not yet provided comprehensive statements to their members suggesting specific ways practitioners could contribute to addressing trafficking and its aftermath.

Because human trafficking appears to be on the rise in a number of countries, and because many individuals who have experienced trafficking may receive legal access to living in new locations, it is possible that a greater number of clients with trafficking backgrounds may seek mental health services. In addition, because of internationalization and globalization affecting mental health professions, clinicians and scholars around the world may become involved in initiatives related to provision of care to victims of trafficking. Thus, this article is intended to be an introductory review on human trafficking for mental health practitioners and scholars. In addition to the review of definitions, causes and processes of trafficking, the article will discuss current guidelines for treatment of survivors of trafficking as well as prevention of trafficking. Although the intended audience of this work will be mainly U.S. practitioners, the material covered will be of importance also to those in other affected settings. It is vital for all practitioners likely to be involved with victims of human trafficking to understand and take note of international perspectives on trafficking.

\title{
Definitions and Scope of Human Trafficking
}

Several definitions of human trafficking have been adopted by international organizations (Gozdziak and Collett 2005). One of the most comprehensive definitions was developed by the United Nations (2000) in its Protocol to Prevent, Suppress, and Punish Trafficking in Persons. In this document, trafficking is identified as

\begin{abstract}
The recruitment, transportation, transfer, harboring or receipt of persons by means of threat or use of force or other forms of coercion, of abduction, of fraud, of deception, of the abuse of power or of a position of vulnerability or of the giving or receiving payments or benefits to achieve the consent of a person having control over another person for the purposes of exploitation. (Article 3, paragraph (a))
\end{abstract}

The focus of this and other most commonly utilized definitions is on the coercion and deception of individuals who are enslaved for sexual, work or other types of exploitation. However, it is important to note that there are definitions of trafficking that incorporate the fact that at times individuals who are trafficked initially enter into such arrangements voluntarily and with consent (such as with internet marriage), although their treatment still meets other criteria for trafficking, such as in the case of prostitution (Gozdziak and Collett 2005; Jahic and Finckenauer 2005).

Much of the current focus, both in the popular media and in the political sphere, is on trafficking related to sexual exploitation (Feingold 2005; Monzini 2005; Poulin 2004). Sexual slavery and exploitation constitute a tremendous violation of human rights, and typically have horrific effects on victims (Poulin 2004). However, experts indicate that in fact trafficking for forced labor is likely to be more widespread around the world (Bales 2005; Feingold 2005; Ruwanpura and Rai 2004).

According to the UN (2007), human trafficking now affects "every country in the world," and even the limited data on trafficking show that the number of victims has reached "epidemic proportions" (p. 18). Obtaining reliable statistics on how many indi- 
viduals are trafficked around the globe is problematic (Gozdziak and Collett 2005; Jahic and Finckenauer 2005; Loff and Sanghera 2004). For example, some demographers include individuals who have been smuggled across national borders for migrant labor, while others only include those who were trafficked for sexual exploitation (Jahic and Finckenauer 2005). Researchers also struggle with what constitutes coercion, as well as with differentiating between adults and children (Loff and Sanghera 2004).

Most international organizations, such as the UN and IOM, rely on data provided by the U.S. Department of Justice. The 2006 Report by that agency estimated that approximately 800,000 individuals were trafficked annually around the globe. Furthermore, the ILO (2005) in its writing on trafficking related to forced labor provides figures as high as 12 million a year. In the words of Gozdziak and Collett (2005), the definitions of trafficking are often "messy," and the statistics about the phenomenon are "slippery" and "ridden with methodological problems" (p. 107). Nevertheless, trafficking in human beings appears to be on the rise and taking on new forms around the world (Raymond and Hughes 2001; Shelley 2003).

\section{Causes and Processes of Trafficking}

Most experts and organizations agree that the current rise in trafficking in human beings is related to globalization, which has created conditions demanding greater supply of individuals for cheap labor and the sex industry (Bales 2005; Monzini 2005; Omelaniuk 2005). Social and economic inequalities that have been progressively increasing around the world, both between and within countries, have especially affected people in countries deemed "developing" (Omelaniuk 2005). The UN (2007) suggests that trafficking disproportionately affects vulnerable communities and individuals in those communities, as well as people living in conflict zones. In addition, new technologies along with mobility of capital have contributed to an unprecedented rise in criminal organizations, which have been viewed as primary mechanisms for trafficking in human beings (Hughes 2001; Poulin 2004; Shostko 2003). According to Vayrynen (2003), human smuggling is a worldwide highly-lucrative business employing millions of individuals and collecting billions of dollars in profits. Additionally, growing restrictions on legal immigration juxtaposed with an increased demand for inexpensive labor has been viewed as a cause of a recent rise in trafficking of people for forced labor (Bales 2005; ILO 2005).

According to Omelaniuk (2005), IOM data show that nearly $80 \%$ of those trafficked are women, and $75 \%$ are 25 years old or younger. Seelke and Siskin (2008) highlight that trafficking can occur in multiple ways: individuals could be kidnapped as well as lured or enticed with false promises of paying jobs. Hughes and Denisova (2002) also report that individuals may be drawn into trafficking through such sophisticated methods as apparently legal "modeling" schools, tourist agencies, or seemingly reputable sources for international jobs.

When trafficked across international borders, individuals are usually provided documentation and transportation, and taken to several transitional locations before arriving at their final destination (Monzini 2005). During their transit and after their arrival, individuals typically are stripped of their documents, required to pay considerable fees for transport, frightened, tortured, humiliated, threatened and abused, culminating in their enslavement (Monzini 2005; Omelaniuk 2005; Seelke and Siskin 2008). Women and children trafficked for sexual exploitation typically are sexually tortured, raped, starved, confined, secluded and forced to have unprotected sex with multiple sexual partners 
(Monzini 2005; Omelaniuk 2005; Seelke and Siskin 2008). Many are also forcibly made to use drugs (Monzini 2005; Seelke and Siskin 2008). Those trafficked for purposes of forced labor can be similarly physically and mentally abused as well as confined, secluded and made to work in brutal conditions and for long hours (Seelke and Siskin 2008).

Those individuals who are found and returned to their home communities often face additional difficulties. Many countries have no or inconsistent laws and regulations regarding the identification and treatment of trafficked individuals (Omelaniuk 2005). When returned, individuals may be spurned by their home communities and their families, especially in the case of sexual trafficking, forcing individuals into conditions that make them again vulnerable to being trafficked (Hughes and Denisova 2002; Monzini 2005). For example, studies in Ukraine show that $75 \%$ of families would shun a child who was known to be involved in prostitution, even if involuntary (Hughes and Denisova 2002). In addition to these difficulties being increasingly addressed by non-governmental organizations and international human rights organizations in trafficked individuals' home communities, much can be done by those countries considered to be receiving communities, such as the U.S. or the countries of the European Union. The following review offers suggestions for the possible roles and functions of mental health professionals and their organizations in attending to issues related to trafficking, such as rehabilitation of victims, prevention of trafficking and becoming involved in local, national and international efforts to stop these violations of human rights.

\section{Mental Health Services for Victims of Trafficking}

It is clear that the mental health consequences related to experiencing the trauma of trafficking are dire. Severe psychological and physical abuse, as well as struggling to survive under extreme and at times life-threatening conditions, marks the typical context of trafficking (Hughes and Denisova 2002; IOM 2002; Monzini 2005; UN 2007). IOM (2002) reports show that typical victims of trafficking experience many symptoms reported by those who have experienced torture, such as psychosomatic reactions, psychological reactions, psychoactive substance abuse and dependence, social reactions and psychophysical consequences of STDs or injuries. A study by Bezpalcha (2003) identified the following range of reactions: fear, guilt, rage, sense of betrayal, distrust, helplessness, shock, suspicion and feeling lost. An IOM (2003) study involving trafficked women in Kosovo showed that individuals also may experience a sense of apathy/resignation, extreme forms of submissiveness to any authority, maladaptation in all social situations, and loss of personal initiative or autonomy. This study also showed that such individuals tended to turn to self medication through substances as well as being much more likely to inflict self-harm or to commit suicide. However, this study also highlighted that victims of trafficking often possessed resilience and a quest for meaning that facilitated their healing and adaptation.

Many of the current guidelines for assistance to victims of trafficking highlight the significance of psychological help (e.g., Anti-Slavery International 2005). Special attention in this regard has been given to the identification of and servicing the child victims of trafficking (Bump et al. 2005; Loiselle et al. 2006). However, existing guidelines appear to focus primarily on actions by law enforcement personnel and humanitarian and social agencies seeking to provide victims with basic needs, such as safety and shelter, as well as more fundamental legal and economic resources. Focus on repatriation to their home community is often primary. Thus, although psychological rehabilitation is frequently highlighted as being vital to victims' healing and integration, it seems to receive only minimal attention and resources. 
Aron et al. (2006) reported that victims often indicated that they wished to receive some type of counseling treatment, especially after their sense of safety and normalcy was re-established. In their study, those who received counseling reported "many positive outcomes, including a stronger sense of self and a feeling that that they have grown stronger from having survived the trafficking experience and coped with its aftermath" (p. 20).

Several key areas appear to be repeatedly highlighted in relation to the training and expertise of those mental health providers who may work with victims of trafficking. First, it is clear that such clinicians must have training in working with victims of trauma, especially sexual and interpersonal trauma (Aron et al. 2006; Monzini 2005; Omelaniuk 2005). Second, it seems evident that clinicians also must work in inter-disciplinary teams, especially involving law enforcement personnel (Van Impe 2001). The Attorney General's Guidelines for Victim and Witness Assistance (U.S. Department of Justice 2005) provides specific instructions for assisting victims of trafficking, which include provisions from the Trafficking Victims Protection Act of 2000, special visas that allow non-immigrant victims of crime to gain legal immigrant standing if they collaborate with investigations, and creation of non-restricting non-prison detention centers. Thus, a general awareness of current immigration policies and access to immigration-based assistance may be important for a clinician. Collaboration with social agencies that can provide such clients with access to legal, economic, vocational, and other vital life resources is also important.

Lastly, clinical work with victims of trafficking is most likely to include cross-cultural encounters. A study by Aron et al. (2006) showed that those individuals who were dissatisfied with their mental health treatment options primarily highlighted the lack of cultural appropriateness and sensitivity on the part of their clinicians. Not only should counselors have strong multicultural counseling competencies in general (i.e., knowledge, awareness and skills), they should specifically be aware of the distinct nature of providing care to immigrant individuals (Bemak and Chung 2002; Prendes-Lintel 2001; Yakushko 2009; Yakushko et al. 2008). For example, counselors may need to seek training in how to work through interpreters.

In regard to provision of direct services, Shigekane (2007) has noted that services to victims can be approached either as an assistance to refugees who survived torture or as victims of domestic violence. Indeed, because centers specific to human trafficking victims often do not exist, victims of human trafficking are typically served by organizations such as domestic violence shelters or refugee assistance programs. Each direct service's approach may have its strengths and limitations.

Growing numbers of refugees to Western countries have resulted in an increase of scholarly literature on the unique aspects of clinical work with this population. Bemak and Chung (2002) suggested a multilevel model of counseling and psychotherapy that specifically focuses on mental health services for refugees. According to them, therapists engaged in working with refugees must have a set of skills that, in addition to individual, family and group modalities, must include training in working with severe trauma. Therapists' skills must be rooted in cultural empathy. Therapists' cultural awareness should encompass an understanding of the diversity of worldviews, family/community/social processes, and ethnic identity. Lastly, competence in working with refugees involves the possession of a political awareness and familiarity with immigration and resettlement policies. Bemak and Chung further highlight that therapists must pay attention to refugee clients' particular experiences, which include their sociopolitical background, historical conditions, premigration trauma, past/current stressors, psychosocial adaptation/adjustment, acculturation, conceptualization of mental illness, worldviews and experiences of discrimination. 
According to these authors, service provision to refugees should include mental health education, psychotherapy, cultural empowerment, and integration of Western and indigenous healing methods. Bemak and Chung suggest that these levels of services must be interrelated and utilized concurrently, although mental health education can be included in the initial formation of treatment goals and the working alliance. Moreover, they highlight that creative techniques such as storytelling, projective drawing, relaxation, dream work, role playing, psychodrama, focusing on moral values and gestalt interventions have been successfully utilized with refugee clients by clinicians who work with this population. Working within the context of families and communities is also emphasized. For example, as a supplement to traditional therapy that focused on anger management with an adolescent Vietnamese male refugee who was a practicing Buddhist, a referral to a Buddhist monk was an effective collaborative approach that honored community values and worldviews (Bemak and Chung 2002).

Because individuals who are trafficked are indeed migrants who have experienced severe trauma, services to them will resemble those provided to other refugees. However, differences may include dealing with the realities of potentially current threat in the lives of human trafficking victims, as well as different legal challenges such as repatriation or prosecution of perpetrators. Regarding the latter difference, services mentioned resemble those provided to victims of domestic violence. Specifically, victims of domestic violence, similar to victims of trafficking, may be under current threat of abuse and require legal protection as well as assurance of safety. In addition, because of the presence of interpersonal sexual and physical violence, victims of trafficking may benefit from counseling approaches similar to those clients experiencing domestic violence. However, important differences exist. Shigekane (2007) highlights that whereas group services are helpful in treatment of victims of domestic violence, group approaches may have negative results with victims of human trafficking. For example, individuals who have been trafficked may have been encouraged by their traffickers to compete with others who were trafficked or in some cases, participate in their abuse. In addition, significant cultural and social divides, as well as fear of being found by their trafficking network, may prevent victims of trafficking from trusting other victims.

Herman (1992) provided guidelines for those working with victims of trauma inflicted by domestic violence or political terror that could be applied to working with those who have experienced trafficking and slavery. According to Herman, counselors must begin with helping their client to establish safety. Although physical and legal safety may be best achieved through the efforts of legal personnel such as police, counselors could be central in exploring with clients what would constitute a sense of safety for them. For example, clients may experience such post-traumatic difficulties as nightmares or heightened fear, which are likely to contribute to their continued feelings of lacking safety. Addressing these intrapersonal difficulties may assist these individuals in re-establishing awareness of personal boundaries and respect for their human dignity. After the important and possibly lengthy stage of establishing safety, counselors could proceed to the second step, which Herman believes to include the reconstruction of the traumatic story. Victims of human trafficking may be especially reluctant to share their stories with others in their lives such as their families or friends, because of fear of rejection or censure. These individuals may also be afraid to share about their experiences because of fear of retribution from their abusers. Counseling relationships could become a safe confidential container for horrific memories of abuse and trauma. In the last step, Herman emphasizes the importance of restoring connection with clients' communities in their processes of heal- 
ing and recovery. Victims of trafficking may eventually find connections with others who shared their experiences or get involved in organizations that fight trafficking. Herman highlights that counselors can keep in mind that such re-connections with community may result in empowering recovering individuals to make changes not only in their own lives but also to use their experiences for the healing of others.

In addition to these suggestions, counselors may be involved in rehabilitation of individuals who were trafficked in many other ways. Counselors can be key in assessment of victims' mental health status as well as possible effects of physical trauma, such as brain damage. Counselors can work together with other providers in examining the social and cultural repercussions of trauma. For example, counselors could provide victims with a place to discuss their fears or hopes in re-connecting with their families and cultural communities as well as what their trauma means within their cultural framework. The effects of addictions, which may be acquired by individuals who experienced trafficking either as the result of forced use of substances or as the result of their attempt for self-healing, may also be best addressed by counselors who have training in substance abuse. In addition, counselors may specialize in provision of career guidance: they could assist their clients in the important steps of establishing their financial and social independence, which can protect them from possible future instances of trafficking.

In summary, mental health services to victims of trafficking may significantly aid these individuals in healing and re-integration into their new or old environments. Because the number of victims is reaching "epidemic proportions" (U.N. 2007), mental health practitioners may encounter greater numbers of clients with such experiences of trauma. Mental health practitioners may be key in addressing the needs of such individuals separately and as a part of interdisciplinary rehabilitation teams. In addition, clinicians may seek to become more actively involved in national and international efforts to prevent trafficking and to influence policies related to individuals who were trafficked.

\section{Prevention and Policy Involvement}

Many prevention efforts must focus on educating the general population about the tremendous human rights violations associated with trafficking. The U.N. (2002) suggestions for prevention of trafficking for countries of destination include such provisions as creation of hotlines staffed by trained professionals, education of media personnel in order to reduce stereotypes related to trafficking, and inclusion of training and awareness-raising of varied agencies and individuals such as mental health professionals. In addition, these suggestions highlight the importance of addressing the rising demand for cheap labor, including that for sexual services. For example, Hughes (2001) highlights the relation between a growing demand for sexually explicit materials, including pornography and child pornography, and new web technologies, which is resulting in an increasing number of trafficked and enslaved individuals used for such services. Thus, along with other informed citizens, mental health practitioners can work to create zero-tolerance policies toward any kind of trafficking, including trafficking related to individuals' sexually predatory actions (e.g., viewing child pornography via internet or participating in sex tourism). Lastly, the U.N. (2002) emphasizes that one of the key areas of prevention that must occur in both trafficking destination countries as well as in countries where trafficking originates is better legal provisions for migration, as well as active combat against "violence and discrimination against women and children" (p. 87). Mental health practitioners and scholars are in an excellent 
position to voice their professional and personal opinions on these matters because of their understanding of the significance of the elimination of prejudice, violence, and discrimination against positive human functioning, and their awareness of the effects of exploitation and violence on individuals, communities and societies.

Another venue for action for mental health practitioners and scholars may be through policy-related actions. Specifically, current provisions for victims of trafficking in most if not all countries do not include ready access to mental health services (Raymond and Hughes 2001). Provision for interpreters to help work with such victims is often required, and where they are available they are usually trained in legal language translation but not in the nuances of mental health-related language. Inclusion of provisions for mental health services as well as a requirement for the training of interpreters in mental health perspectives, as well as the specialized training of providers, will contribute to the betterment of individuals who have experienced such trauma.

Lastly, because international borders are becoming more permeable due to greater access to technologies and increased migration, greater numbers of professionals may be seeking involvement with international human rights organizations. As mentioned earlier, the U.N. and the IOM are among a considerable number of international organizations that have committed their resources and personnel to addressing a wide range of trafficking-related concerns around the world. In addition, many countries have local non-governmental organizations working to stop trafficking and rehabilitation of its victims. These organizations often focus on mental health needs of individuals and communities they serve, and may welcome the participation of suitably trained clinicians and scholars.

\section{Conclusion}

If trafficking of human beings is indeed an epidemic (UN 2007), then mental health providers and scholars have to rise to its challenge in order to add their skills and their voices to ending such exploitation and violence and diminishing its aftermath. It seems unthinkable to imagine that nearly a million or more children, women and men are enslaved and tortured each year in demand for their bodies. These individuals may find their way to clinical offices or research projects and thereby receive direct or indirect assistance. However, for the greater good it is imperative that they are helped to find their ways into the hearts and minds of those who can make a major difference, expanding an awareness of the horrors of trafficking and igniting passion for finding ways to work toward its elimination and the betterment of lives.

\section{References}

Anti-Slavery International. (2005). Protocol for identification and assistance to trafficked persons and training kit. London: Anti-Slavery International.

Aron, L. Y., Zweig, J. M., \& Newmark, L. S. (2006). Comprehensive services for survivors of human trafficking: Findings from clients in three communities. Washington, D.C.: Urban Institute.

Bales, K. (2005). Understanding global slavery. Berkeley: University of California Press.

Bales, K., \& Lize, S. (2005). Trafficking in persons in the United States. Washington, DC: U.S. Department of Justice. Document No. 211980. 
Bemak, F., \& Chung, R. C. (2002). Counseling and psychotherapy with refugees. In P. B. Pedersen, J. G. Draguns, W. J. Lonner, \& J. E. Trimble (Eds.), Counseling across cultures (2nd ed.), pp. 209-232. Thousand Oaks: Sage.

Bump, M., Duncan, J., Gozdziak, E., \& MacDonnell, M. (2005). Second conference on identifying and serving child victims of trafficking. International Migration (Geneva, Switzerland), 43, 344-363. doi: 10.1111/ j.0020-7985.2005.00322.x.

Doezema, J. (2002). Who gets to choose? Coercion, consent, and the UN trafficking protocol. Gender and Development, 10, 20-27. doi: 10.1080/13552070215897.

European Commission. (2004). Report of the experts group on trafficking in human beings. Brussels: European Commission.

Feingold, D. A. (2005). Human trafficking. Foreign Policy, 150, 26-32.

Gozdziak, E. M., \& Collett, E. A. (2005). Research on human trafficking in North America: A review of literature. International Migration (Geneva, Switzerland), 43, 99-128. doi: 10.1111/j.00207985.2005.00314.x.

Herman, J. L. (1992). Trauma and recovery: The aftermath of violence - from domestic abuse to political terror. New York: Basic Books.

Hughes, D. M. (2001). The impact of the use of new communications and information technologies on trafficking in human beings for sexual exploitation: A study of the users. Geneva: Council of Europe.

Hughes, D. M., \& Denisova, T. (2002). Trafficking in Women from Ukraine. Final report to the National Institute of Justice, 2002, NCJ 203275.

ILO (International Labor Organization). (2005). Tools for prevention - participatory monitoring: Guidelines for practitioners in the fight against human trafficking. Bangkok: ILO.

IOM (International Organization for Migration). (2002). Report of the counter-trafficking unit: Return and reintegration project. Brussels: International Organization for Migration.

Jahic, G., \& Finckenauer, J. O. (2005). Representations and misrepresentations of human trafficking. Trends in Organized Crime, 8, 24-40. doi: 10.1007/s12117-005-1035-7.

Kelly, L., \& Regan, L. (2000). Stopping traffic: Exploring the extent of, and responses to, trafficking in women for sexual exploitation in the UK. Police Research Series, Paper 125, Home Office, London.

Loff, B., \& Sanghera, J. (2004). Distortions and difficulties in data for trafficking. Lancet, 363, 566. doi: 10.1016/S0140-6736(04)15548-7.

Loiselle, M., MacDonnell, M., Duncan, J., \& Dougherty, M. E. (2006). Care for trafficked children. Washington, DC: United States Conference of Catholic Bishops.

Monzini, P. (2005). Sex traffic: Prostitution, crime and exploitation. New York: Zed.

Omelaniuk, I. (2005). Trafficking in human beings. New York: The United Nations Expert Group Meeting on International Migration and Development, UN/POP/MIG/2005/15.

Poulin, R. (2004). Globalization and the sex trade: Trafficking and commodification of women and children. Canadian Women's Studies, 22, 38-43.

Prendes-Lintel, M. (2001). A working model in counseling recent refugees. In J. G. Ponterotto, J. M. Casas, L. A. Suzuki \& C. M. Alexander (Eds.), Handbook of multicultural counseling, pp. 729-752. Thousand Oaks: Sage.

Raymond, J. G., \& Hughes, D. M. (2001). Sex trafficking of women in the United States: International and domestic trends. New York: Coalition against Trafficking in Women.

Ruwanpura, K. N., \& Rai, P. (2004). Forced labour: Definition, indicators, and measurement. Geneva: International Labour Office.

Seelke, C. R., \& Siskin, A. (2008). Trafficking in persons: U.S. policy and issues for Congress. Washington, DC: Congressional Research Services. 
Shelley, L. L. (2003). The rise and diversification of human smuggling into the United States. Essays in Honour of Alice Yotopoulos-Marangpoulos. Human Rights Crime-Criminal Policy Volume B, pp. 1191-1204. Athens: Nomiki Bibiliothiki Group.

Shigekane, R. (2007). Rehabilitation and community integration of trafficking survivors in the United States. Human Rights Quarterly, 29, 112-136. doi: 10.1353/hrq.2007.0011.

Shostko, O. (2003). Organized crime in Ukraine: Contemporary situation and methods of counteraction. In S. Nevala \& K. Aromaa (Eds.), Organised crime, trafficking, drugs: Selected papers presented at the annual conference of the European Society of Criminology, HEUNI report \# 42, pp. 216-231. Monsey: Criminal Justice Press. Sami Nevala and Kauko Aromaa.

United Nations (2000). Protocol to prevent, suppress and punish trafficking in persons, especially women and children, supplementing the United Nations Convention against transnational organized crime. Online (November 10, 2008) at http://www.uncjin.org/Documents/Conventions/dcatoc/final_documents_2/ convention \%20traff eng.pdf

United Nations. (2002). Prevention of human trafficking. New York: United Nations.

United Nations. (2007). Feature on human trafficking. New York: United Nations Office on Drugs and Crime.

U.S. Department of Justice. (2005). Attorney General guidelines for victim and witness assistance. Washington, DC: U.S. Department of Justice.

Van Impe, K. (2001). People for sale: The need for a multidisciplinary approach towards human trafficking. International Migration (Geneva, Switzerland), 2001(1), 113-131.

Vayrynen, R. (2003). Illegal immigration, human trafficking, and organized crime. Discussion paper no. $2003 / 72$. Helsinki, Finland: United National University/Wider.

Yakushko, O. (2008). Building collaborations to work on issues related to human trafficking. Psychological Inquiry, 9, 9.

Yakushko, O. (2009). Xenophobia: Understanding the roots and consequences of negative attitudes towards immigrants. The Counseling Psychologist, 37, 36-66. doi: 10.1177/0011000008316034.

Yakushko, O., Watson, M., \& Thompson, S. (2008). Stress and coping in the lives of recent immigrants and refugees: Considerations for counseling. International Journal for the Advancement of Counseling, 30, 167-178. doi: 10.1007/s10447-008-9054-0. 